\title{
PEMANFAATAN TEKNOLOGI AUGMENTED REALITY DALAM PEMASARAN PERUMAHAN MUTIARA BARANGAN PALEMBANG
}

\author{
Pacu Putra ${ }^{1}$, Akbar Alzaini $^{2}$, Rahmat Izwan Heroza ${ }^{3}$, Allsela Meiriza ${ }^{4}$
}

${ }^{1234}$ Jurusan Sistem Informasi, Fakultas Ilmu Komputer, Universitas Sriwijaya

Jl. Palembang - Prabumulih KM.32 Kabupaten Ogan Ilir, Sumatera Selatan

Ipacu89@gmail.com, ${ }^{2}$ akbaralzaini@gmail.com, ${ }^{3}$ rahmatheroza@gmail.com, ${ }^{4}$ allsela_meiriza@yahoo.co.id

Abstrak - Perumahan Mutiara Barangan adalah perumahan yang terletak di tanjung barangan, Palembang, Sumatera Selatan yang dikembangkan oleh PT. Kurnia Hamusri Sukses Mandiri. Perushaan ini menggunakan gambar dalam brosur dan miniatur rumah dalam pemasaranya. Penelitian ini bertujuan untuk menerapkan teknologi augmented reality pada sistem digital marketing untuk melihat visual rumah dalam bentuk 3D. Model pengembangan sistem ini akan mengikuti alur Multimedia Development Life Cycle (MDLC) yaitu concept, design, material collecting, assembly, testing dan distribution. Sebagai hasil dari implementasi teknologi augmented reality dalam pemasaran perumahan Mutiara Barangan Palembang dapat memberikan pengalaman baru bagi pelanggan dalam melihat bentuk rumah yang ditawarkan

Kata Kunci - Augmented Reality, Perumahan, Maker Based, Vuforia

Abstract - Perumahan Mutiara Barangan is a housing complex that located at tanjung barangan, Palembang, Sumatera Selatan that was developed by PT. Kurnia Hamusri Sukses Mandiri. This This enterprise use pictures, brochures, and miniature for marketing activities. The objective of this research was to implement Augmented Reality Technology in digital marketing system to visualize their house in 3Ds View. The System Development model that used in this study is Multimedia Development Life Cycle (MDLC) which consists of concept, design, material collecting, assembly, testing and distribution. As a result of implementing Augmented Reality in Marketing of housing complex in Perumahan Mutiara Barangan Palembang can offer new experience of user in observing housing complex that was offered.

Keywords - Augmented Reality, Perumahan, Maker Based, Vuforia

\section{PENDAHULUAN}

Perumahan merupakan salah satu kebutuhan dasar pada kehidupan manusia, dimana perumahan sendiri menjadi media untuk berlindung serta bersosialisasi. Saat ini tidak bisa dipungkiri lagi banyak sekali perusahaan-perusahaan yang bergerak dibidang perumahan khususnya dalam pengembangan komplek perumahan. Pemilihan perumahan juga tidak hanya sekedar memilih sebagai tempat tinggal saja, namun banyak faktor pendukung dalam menentukan pemilihan rumah, diantaranya dalam menciptakan suasana yang layak huni (livible), aman (safe), nyaman (comfortable), damai (peaceful) dan sejahtera (prosperous) serta berkelanjutan (sustainable). [1]

Adanya dampak Pandemi Covid-19 sangat berpengaruh terhadap penjualanan perumahan. Seperti yang dilansir oleh berita online mediaindonesia.com bahwa pembangunan perumahan di wilayah Sumatera Selatan terjadi penurunan. Salah satu penyebab terjadinya penurunan adalah adanya penurunan daya beli para dikarenakan masa Pandemi ini.[2]

Perumahan Mutiara Barangan merupakan saah satu perusahaan yang bergerak dibidang perumahan yang berlokasi di Tanjung Barangan, Palembang. Dalam penjualanan perumahan pihak perumahan masih mengandalkan adanya pameran-pameran perumahan dan promosi melalui poster-poster. Pihak Perumahan Mutiara Barangan mengakui bahwa terjadinya penurunan jumlah pembelian di masa pandemi ini, karena sangat sulit untuk mempromosikan perumahan secara bertatap muka langsung.

Seiring perkembangan teknologi, banyak teknologi yang telah diciptakan untuk mempermudah pengguna, khususnya dimasa pandemi ini. Salah satu teknologi yang sedang ramai dibicarakan adalah Augmented Reality.

Teknologi Augmented Reality dapat memproyeksikan objek maya terhadap dunia nyata [3]. Augmented Reality juga dapat menambah nilai persepsi pengguna terhadap sebuah objek[4]. Karena keterbasan di masa pandemi, Augmented Reality dapat dimanfaatkan perusahaan perumahan dalam mempromosikan produknya secara virtual[5].

Pada penelitian ini, peneliti menerapkan teknologi Augmented Reality dalam pemasaran perumahan Mutiara Barangan Palembang. Fitur-fitur yang dihasilkan dari penelitian ini dapat dimanfaatkan dalam mempromosikan penjualanan rumah dimasa pandemi. 


\section{METODE PENELITIAN}

Metode penelitian yang digunakan pada penelitian ini adalah metode MDLC (Multimedia Development Liefcycle). Metode MDLC memiliki 6 tahap yang dimulai dari konsep, kemudian penentuan desain, Page|182 pengumpulan materi, pembuatan, pengujian, serta pendistribusian yang ditampilkan pada Gbr1.[6], [7].

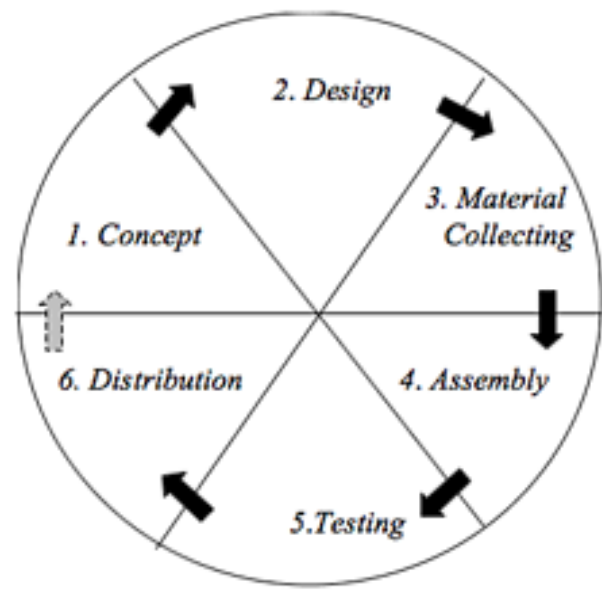

Gbr.1 Multimedia Development Lifecycle

\section{Concept}

Tahapan awal pada penelitian ini adalah konsep. Pada fase ini beberapa aktivitas yang dilakukan antara lain, penentuan tujuan dan siapa pengguna sistem dengan menggunakan beberapa metode seperti wawancara, studi pustaka, dan observasi.

\section{Design}

Tahapan yang kedua pada penelitian ini adalah design. Pada fase ini pembuatan perancangan logika dengan menggunakan UML (Unified Modelling Language). Selain itu, penggunaan storyboard dapat membantu dalam membuat desain user interface dari system yang dibuat.

\section{Material Collecting}

Pada tahap dilakukan pengumpulan bahan atau material yang diperlukan untuk membuat sistem. Tahap ini akan dikerjakan secara paralel dengan tahap assembly.

\section{Assembly}

Tahapan ini merupakan tahapan dimana material multimedia digunakan. Pembuatan sistem serta antarmuka aplikasi didasarkan pada tahap desain. Pada tahapan ini dilakukan pembuatan 3D Object, pengkodean aplikasi, pembuatan target manager, pembuatan Canvas antarmuka unity, pembuatan aplikasi Android, pembuatan Augmented reality, virtual button dan pembuatan APK aplikasi.

Testing

Setelah tahap assembly, untuk memastikan bahwa aplikasi berjalan sesuai konsep yang telah dibuat, maka aplikasi akan dilakukan testing. Testing yang dilakukan pada fase ini adalah blackbox testing. Dimana pada pengujian blackbox testing, memastikan fungsi-fungsi pada aplikasi berjalan sesuai dengan konsep.

\section{Distribution}

Aplikasi yang telah berhasil dibangun pada fase akhir ini akan dipublikasi melalui beberapa media. Salah satu media yang digunakan adalah meletakkan aplikasi tersebut pada Play Store, agar pengguna dapat melakukan download dan instalasi sendiri.

\section{HASIL DAN PEMBAHASAN}

Hasil dari penelitian ini yang pertama adalah Use Case Diagram yang menjelaskan kelakuan atau behaviour aplikasi yang dibangun. Pada Gbr 2 ditunjukkan terdapat Sembilan use case proses dan satu aktor. Sembilan Use Case tersebut antara lain adalah melihat daftar rumah, melihat augmented reality, melihat informasi rumah, mengganti warna cat dinding, mengganti cat panel, membuka atap rumah, menampilkan deskripsi, menampilkan palette cat, dan keluar aplikasi.

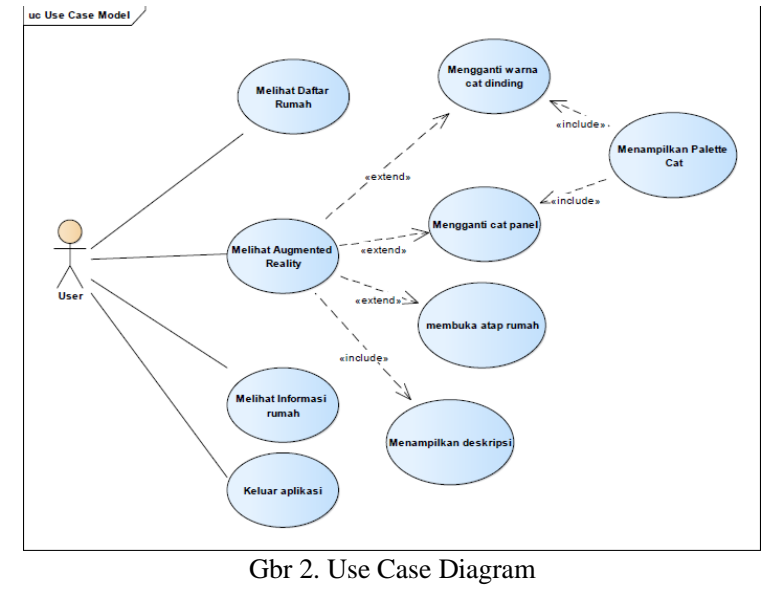

Selain Use Case, pada rancangan logika penelitian ini juga menghasilkan rancangan diagram kelas yang dapat dilihat pada Gbr 3. Adapun kelas-kelas yang terdapat didalam aplikasi yang dikembangkan antara lain, DetailRumahActivity, MainActivity, Augmented Reality, ChangeColor, PanelCat, MenuAR, dan Object Hidden. 


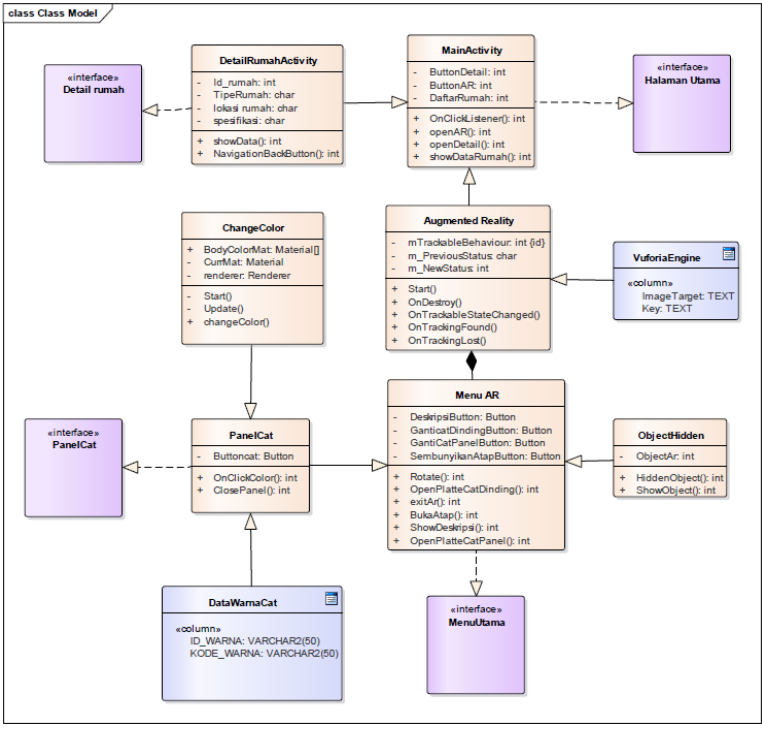

Gbr 3. Class Diagram

Untuk tampilan aplikasinya dapat dilihat pada $\mathrm{Gbr}$ 4, dimana terdapat beberapa menu yang dapat diakses. Menu-menu tersebut antara lain denah, lokasi, kontak, video, informasi, AR Camera dan foto tipe rumah yang tersedia. Untuk menampilkan fungsi Augmented Reality menu yang dipilih adalah AR Camera

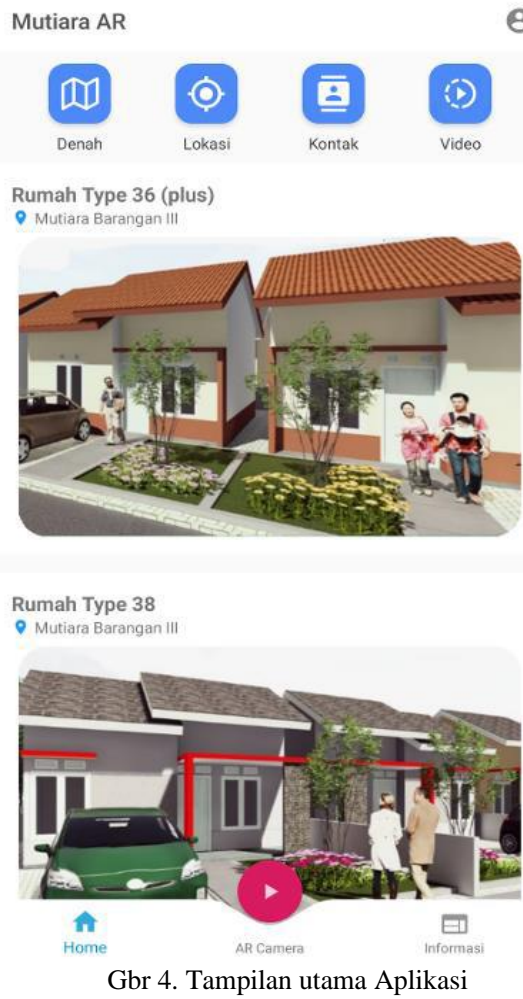

Pada halaman ARCamera menampilkan object 3D rumah berdasarkan denah rumah yang menjadi marker Augmented Reality-nya. Pengguna disediakan beberapa tombol untuk berinteraksi dengan objek 3D, diantaranya Deskripsi, Buka Atap, Cat Panel, Cat Dinding.

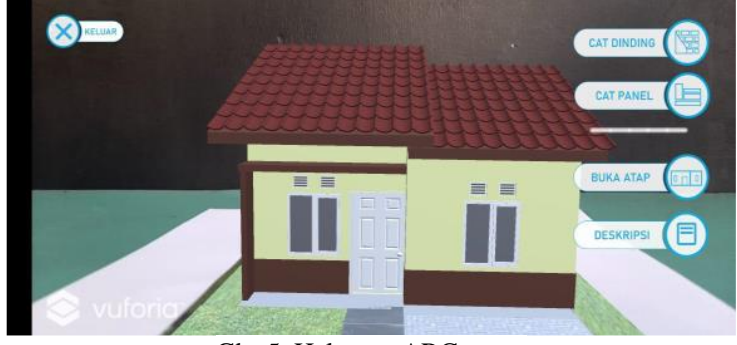

Gbr 5. Halaman ARCamera

Untuk menampilkan object rumah 3D, teknologi Augmented Reality yang digunakan berbasis marker. Terdapat beberapa marker yang digunakan untuk menampilkan object rumah 3D yang berbeda, diantaranya yang ditampilkan pada Gbr 6 .

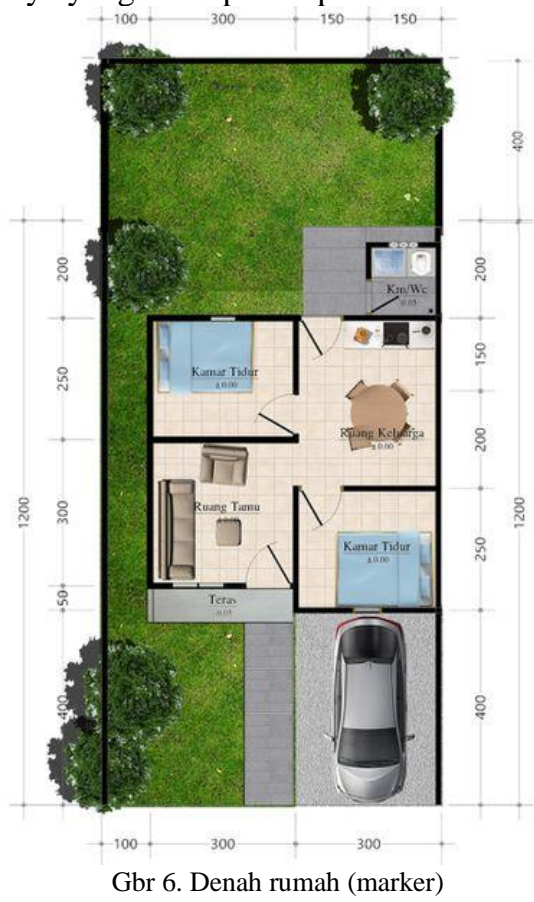

Menu Deskripsi yang terletak paling bawah berfungsi untuk menampilkan detail informasi kaitan dengan tipe rumah. Informasinya sendiri bersifat float (mengambang), ini bermaksud agar pengguna dapat melihat informasi detail sekaligus dapat melihar object $3 \mathrm{~d}$ rumah tersebut.

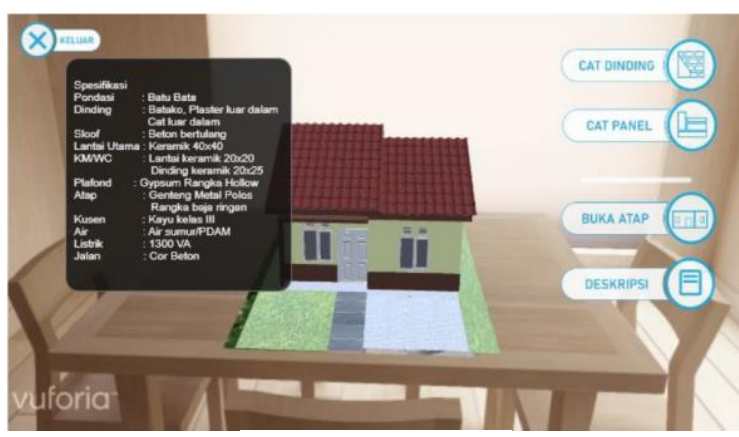

Gbr 7. Deskripsi Rumah 
Menu Buka Atap dapat menghilangkan gambar Atap dengan tujuan dapat melihat detail isi rumah secara 3D. Hal ini diharapkan dapat membuat pengguna lebih tertarik akan perumahan ini.

Page | 184

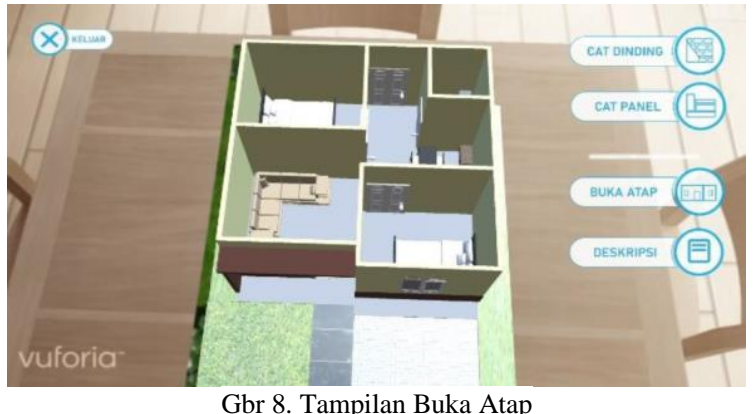

Menu berikutnya yaitu cat dinding dan cat panel. Pada menu ini pengguna dapat melakukan custom warna dinding dan panel-panel rumah sesuai warna yang diinginkannya. Dapat dilihat pada Gbr 9 warnawarna yang dapat dipilih oleh pengguna untuk mendapatkan cat rumah sesuai keinginnannya. Adapun warna-warna yang digunakan pada platte tersebut berdasarkan salah satu produsen cat di Indonesia.

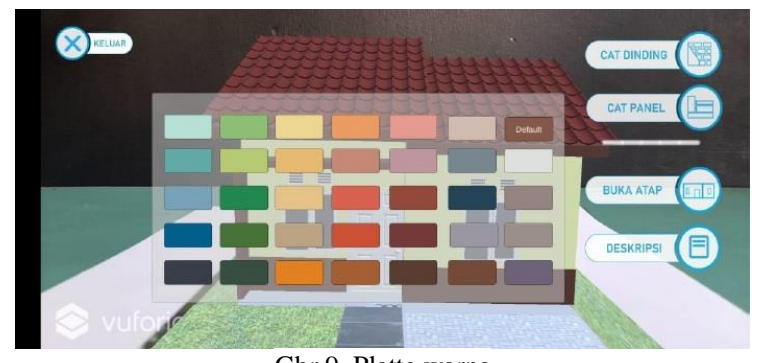

Aplikasi ini sendiri telah didistribusikan melalui Playstore yang dapat diunduh secara bebas. Hal ini bertujuan apabila ada peneliti lain yang berminat untuk melakukan penelitian yang terkait dengan aplikasi yang telah dibangun, dapat mengaksesnya secara mudah.

\section{KESIMPULAN}

Berdasarkan hasil penelitian, dengan diterapkannya augmented reality pada aplikasi digital marketing perumahan mutiara baragan dapat memeberikan pengalaman baru pada pelanggan mutiara barangan dalam melihat pemasaran property perumahan. Dan Aplikasi digital marketing yang menerapkan Augmanted reality dapat menjadikannya sebagai strategi marketing baru pada pelanggan, sehingga dapat memberikan pengalaman yang baru pada pelanggan.

Dalam penelitian hanya mengembangkan sebuah aplikasi yang mengimplementasi teknologi Augmented Reality. Untuk penelitian kedepannya dapat dilakukan pengukuran terhadap keefektifan pemasaran perumahan dengan menggunakan teknologi Augmented Reality.

\section{UCAPAN TERIMAKASIH}

Ucapan terima kasih disampaikan kepada pihak yang membiayai penelitian ini dalam skema penelitian sains, teknologi, dan seni di tahun 2020

\section{REFERENSI}

[1] S. H. Kusuma, "Arahan Pengembangan Perumahan dan Kawasan Permukiman di Kabupaten Probolinggo, berdasarkan Kesesuaian Lahan," J. Penataan Ruang, vol. 12, no. 1, pp. 41-47, 2017, doi: http://dx.doi.org/10.12962/j2716179X.v12i1.5223.

[2] D. Apriani, "Realisasi Pembangunan Rumah di Sumsel Turun," Media Indonesia, Palembang, Nov. 23, 2020.

[3] S. D. Riskiono, T. Susanto, and K. Kristianto, "Rancangan Media Pembelajaran Hewan Purbakala Menggunakan Augmented Reality," CESS (Journal Comput. Eng. Syst. Sci., vol. 5, no. 2, p. 199, 2020, doi: 10.24114/cess.v5i2.18053.

[4] I. F. Noor, H. Tolle, and W. S. Wardhono, "Rancang Bangun Aplikasi Augmented Reality Pemilihan Sepatu Berdasarkan Ukuran Kaki Pengguna," $J$. Pengemb. Teknol. Inf. dan Ilmu Komput., vol. 2, no. 4, pp. 1675-1682, 2018, [Online]. Available: http://jptiik.ub.ac.id/index.php/j-ptiik/article/view/1320.

[5] M. Muntahanah, R. Toyib, and M. Ansyori, "Penerapan Teknologi Augmented Reality Pada Katalog Rumah Berbasis Android (Studi Kasus PT. Jashando HAN Saputra)," Pseudocode, vol. 4, no. 1, pp. 81-89, Feb. 2017, doi: 10.33369/pseudocode.4.1.81-89.

[6] I. Binanto, Multimedia Digital - Dasar Teori dan Pengembangannya. Yogyakarta: Andi, 2010.

[7] M. Mustika, E. P. A. Sugara, and M. Pratiwi, "Pengembangan Media Pembelajaran Interaktif dengan Menggunakan Metode Multimedia Development Life Cycle," J. Online Inform., vol. 2, no. 2, p. 121, Jan. 2018, doi: 10.15575/join.v2i2.139. 